\title{
Structure and Function of the Mucus Clearance System of the Lung
}

\author{
Brenda M. Button ${ }^{1}$ and Brian Button ${ }^{2}$ \\ ${ }^{1}$ Departments of AIRmed and Physiotherapy, The Alfred Hospital, Department of Medicine, Monash University, \\ Melbourne, Australia \\ ${ }^{2}$ Cystic Fibrosis Research and Treatment Center, University of North Carolina, Chapel Hill, North Carolina 27599 \\ Correspondence: b.button@alfred.org.au; bbutton@med.unc.edu
}

In cystic fibrosis (CF), a defect in ion transport results in thick and dehydrated airway mucus, which is difficult to clear, making such patients prone to chronic inflammation and bacterial infections. Physiotherapy using a variety of airway clearance techniques (ACTs) represents a key treatment regime by helping clear the airways of thickened, adhered, mucus and, thus, reducing the impact of lung infections and improving lung function. This article aims to bridge the gap between our understanding of the physiological effects of mechanical stresses elicited by ACTs on airway epithelia and the reported effectiveness of ACTs in CF patients. In the first part of this review, the effects of mechanical stress on airway epithelia are discussed in relation to changes in ion transport and stimulation in airway surface layer hydration. The second half is devoted to detailing the most commonly used ACTs to stimulate the removal of mucus from the airways of patients with CF.

\section{REGULATION OF AIRWAY SURFACE HYDRATION}

The hydration state of the airway mucus layer
is crucial for regulating the rate of mucocili-
ary clearance (MCC) in the lung (Boucher
2007b). In the airways, the hydration state of
the airway surface layer (ASL) fluid is controlled
by the ion channels that regulate the mass of salt
and water on the airway surfaces. Airway epithe-
lia are highly water permeable because of their
low transepithelial electrical resistances (Bou-
cher 1994) and high expression of aquaporins
(Kreda et al. 2001). The advantage of such epi-
thelia is that they are capable of both absorbing
fluid and secreting fluid, depending on the di-
rection of the salt transport across airway epithe- lia. Because the concentration of $\mathrm{NaCl}$ within the ASL is essentially isotonic, the overall mass of $\mathrm{NaCl}$ in the ASL is critical for determining the total fluid volume of the ASL (Boucher 2007a). For example, if more salt is secreted into the ASL by the epithelium, water follows passively and the ASL volume will rapidly increase to maintain isotonicity. Conversely, if $\mathrm{NaCl}$ is absorbed, water also follows passively, resulting in a dehydration of the ASL. This ability to alternate between fluid absorption and secretion allows the airway epithelia to fine-tune the hydration state of the ASL and ensure efficient MCC.

Indeed, airway epithelia are capable of optimizing ASL hydration state by modifying the activities of apical ion channels to switch continuously between secretory and absorptive

Editors: John R. Riordan, Richard C. Boucher, and Paul M. Quinton

Additional Perspectives on Cystic Fibrosis available at www.perspectivesinmedicine.org

Copyright (C) 2013 Cold Spring Harbor Laboratory Press; all rights reserved; doi: 10.1101/cshperspect.a009720

Cite this article as Cold Spring Harb Perspect Med 2013;3:a009720 
phenotypes (Button et al. 2007). In the airways, fluid absorption from the luminal airway surface to the submucosal compartment is regulated by net $\mathrm{Na}^{+}$absorption, mediated by the amiloride-sensitive epithelial sodium channel (ENaC) (Davis and Matalon 2007), whereas chloride $\left(\mathrm{Cl}^{-}\right)$secretion across the apical membrane provides the driving force for net fluid secretion onto the airway surfaces. In the airways, $\mathrm{Cl}^{-}$secretion is mediated by the cystic fibrosis transmembrane conductance regulator (CFTR), a member of the ATP-binding cassette (ABC) family of channels/transporters (Greger et al. 2001), and the calcium-activated chloride channel (or CaCC), which has been identified as TMEM16A, a member of the anoctamin family of anion channels (Rock et al. 2009).

\section{DEFECTIVE ASL HYDRATION REGULATION IN CYSTIC FIBROSIS}

In cystic fibrosis (CF), mutations of the gene coding CFTR are associated with a significant decrease in epithelial $\mathrm{Cl}^{-}$secretion and excess $\mathrm{Na}^{+}$absorption (Boucher 2007a). The depletion of the ASL causes an excessive concentration of the mucus layer. When mucus concentrates, increases in its osmotic pressure results in drawing water osmotically from the PCL, collapsing the PCL and folding over the cilia. The sequence renders cilia ineffective at coordinated beating activity and thus unable to clear the adherent thickened mucus (Boucher 2007b; Button et al. 2012). This immobilization results in the apposition of the mucus layer to the cellsurface PCL, which has been hypothesized to lead to a physical interaction (adhesion) that is sufficiently strong to resist mucus clearance via ciliary beating or coughing. Stasis of lung secretions in CF eventually leads to mucus plugging, chronic bacterial infection and inflammation, and eventually, airway damage (bronchiectasis).

\section{REGULATION OF ASL HYDRATION BY EXTRACELLULAR NUCLEOTIDES/ NUCLEOSIDES}

Airway epithelia appear to be disconnected from the effects of systemic hormones that are known to regulate ion transport rates in other epithelia, including being resistant to the actions of mineralocorticoid and steroid hormones (Grubb and Boucher 1998). In contrast, airway epithelia rely on local extracellular signals in the ASL itself to maintain the ASL hydration state sufficient for basal mucus clearance, as well as report the stresses on airway surfaces that require an adjustment of ASL hydration and mucus clearance.

Key players in ASL hydration regulation that have been extensively characterized are the luminal concentrations of adenosine-based nucleotides (e.g., ATP or UTP) and nucleosides (e.g., adenosine [ADO]) (Schmid et al. 2011). These molecules act as major autocrine regulators of mucus clearance by their ability to modulate the activity of ion channels/transporters involved in ASL volume homeostasis. Specifically, studies have shown that exogenous application of ATP, UTP, or ADO produces coordinate regulatory effects on airway epithelia ion transport, including the inhibition of $\mathrm{Na}^{+}$ absorption and activation of $\mathrm{Cl}^{-}$secretion (Knowles et al. 1991; Benali et al. 1994), resulting in net secretion of fluid onto the airway surface. Indeed, inhaled UTP (and its derivatives) has been shown to stimulate both mucus clearance (Bennett et al. 1996) and sputum production (Johnson et al. 2002) in patients with obtrusive lung diseases.

The stimulation of net fluid secretion by nucleotides and nucleosides occurs via the activation of G-protein-coupled ATP-sensitive $\mathrm{P}_{2} \mathrm{Y}_{2}$ and ADO-sensitive $\mathrm{A}_{2 \mathrm{~b}}$ purinoceptors, located in the luminal membrane of superficial airway epithelial cells (Lazarowski and Boucher 2001, 2009). Stimulation of $\mathrm{P}_{2} \mathrm{Y}_{2}$ receptors by extracellular ATP results in the activation of a heterotrimeric $\mathrm{G}$ protein $\left(\mathrm{G}_{\mathrm{q}}\right)$ that increases the activity of both CaCC (TMEM16A), via an $\mathrm{IP}_{3}$ dependent increase in intracellular calcium $\left(\mathrm{Ca}_{\mathrm{i}}{ }^{2+}\right)$ and CFTR, by a PKC-dependent mechanism (Fischer et al. 1998). In contrast, ENaC has been shown to be inactivated by $\mathrm{P}_{2} \mathrm{Y}_{2}$ receptor activation (Stutts et al. 1995) via depletion of $\mathrm{PIP}_{2}$ (Kunzelmann et al. 2005). The net effect is the stimulation of fluid secretion in the airways, facilitating mucus clearance. In addition 
to changes in ion transport by ATP, activation of $\mathrm{P} 2 \mathrm{Y}_{2}$ receptors can modulate the activity of other cellular processes, including stimulation in mucin secretion (Davis 2002) and increasing the rate of ciliary beating (Morse et al. 2001).

Adenosine, a product of ATP metabolism by extracellular enzymes (Picher et al. 2004), has also been shown to be a potent extracellular regulator of airway hydration state via the activation of $G$-protein $\left(G_{s}\right)$-coupled $A_{2 b}$ purinoceptors on the luminal surface (Lazarowski et al. 1992). In airways, $A_{2 b}$ stimulation results in cAMP-dependent activation of CFTR (Hanrahan et al. 1996) and inhibition of ENaC-mediated $\mathrm{Na}^{+}$absorption (Kunzelmann et al. 2001).
As with ATP, the net effect of increases in extracellular ADO is the stimulation of fluid secretion onto the airway surface.

Figure 1 presents a simplified schema depicting how these elements are integrated to participate in regulating the ATP/ADO levels, ASL hydration state, and, hence, the rate of mucus clearance from the lung. During conditions of ASL dehydration, the concentrations of ATP/ $\mathrm{ADO}$ are elevated, resulting in a stimulation of fluid secretion. In contrast, the presence of " $\mathrm{ex}$ cess" fluid on the airways dilutes the extracellular ATP/ADO, resulting in net fluid absorption until the concentrations of ATP/ADO are sufficient to activate purinoceptors.

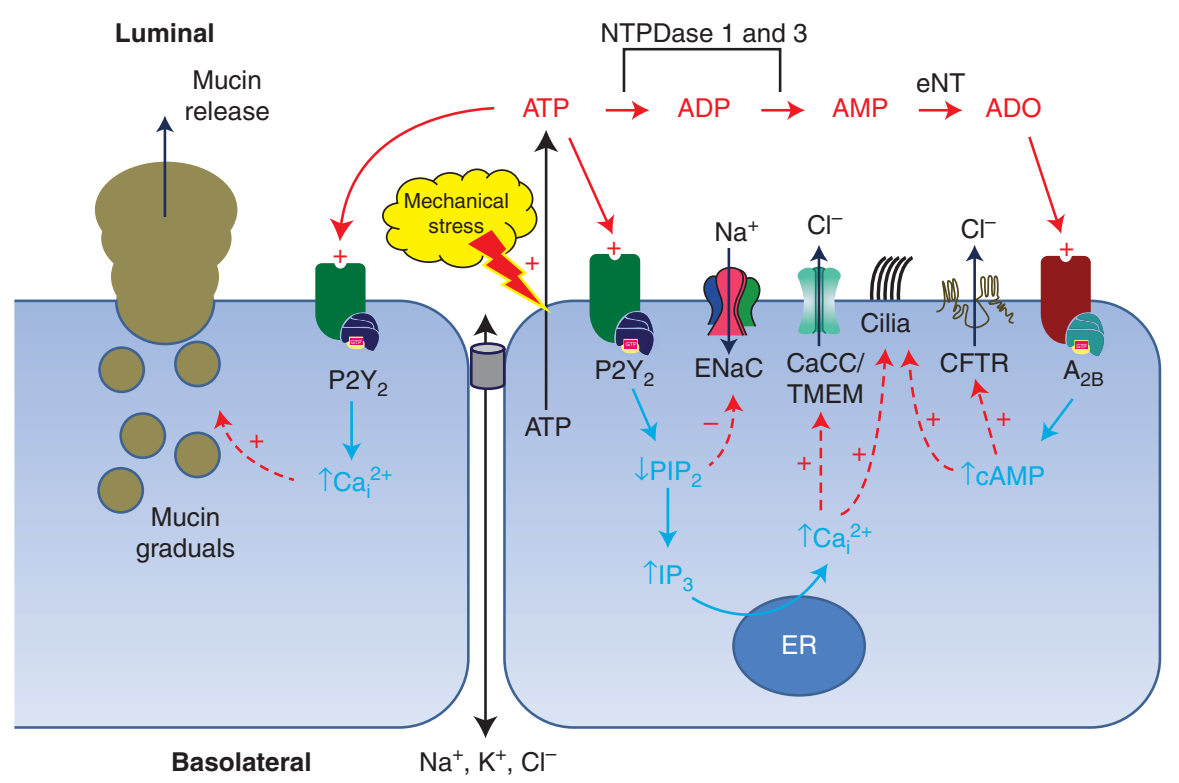

Figure 1. Model of purinergic signaling in airway epithelia. Mechanical stimulation of the epithelial surface by mechanical stress, irritants, or pathogens induces ATP release and elevates ASL (ATP). ATP is an agonist to a series of purinoceptors, including the G-protein-coupled $\mathrm{P}_{2} \mathrm{Y}_{2}$ receptor located on the luminal surface of the airway lumen. Upon $\mathrm{P}_{2} \mathrm{Y}_{2}$ receptor activation, the rate of $\mathrm{PIP}_{2}$ hydrolysis increases, resulting in an increase in $\mathrm{IP}_{3}$ and release of $\mathrm{Ca}^{2+}$ from stores. Increased levels of intracellular $\mathrm{Ca}^{2+}$ are responsible for activating CaCC (TMEM16a), resulting in a stimulation in $\mathrm{Cl}^{-}$secretion. Additionally, the reduction in PIP2 also results in a decrease in ENaC-mediated sodium absorption. The action of a series of ectonucleotidases converts the extracellular ATP to ADP, AMP, and eventually adenosine (ADO). Adenosine is a potent agonist of adenosine receptors, such as the $A_{2 b}$ receptor, expressed on the airway surface. Activation of these receptors induces Gprotein-coupled adenylate cyclase, followed by cAMP-dependent activation of protein kinase A. The result is stimulation of CFTR-mediated $\mathrm{Cl}^{-}$secretion. In addition to modulation of ion channel activity, stimulation of ATP release is a well-known agonist for stimulating mucin release (via $\mathrm{P}_{2} \mathrm{Y}_{2}$ receptor activation) and cilia beat frequency (via both $\mathrm{P} 2 \mathrm{Y}_{2}$ and $\mathrm{A}_{2 \mathrm{~b}}$ ). Together, the action of mechanical stress is the stimulation of fluid secretion and acceleration of mucus transport rates. 


\section{STIMULATION OF ATP RELEASE BY MECHANICAL STRESSES}

By virtue of their interfacial position in the lungs, the epithelial cells lining the airway are ideally situated to act as sensors of breathingdependent changes in mechanical stress (such as airflow, stretching, and pressure). The role of mechanical forces in pulmonary health raises the possibility of relationships between the forces generated by tidal breathing, airway surface hydration, and the rates of mucociliary clearance.

As a mechanism to link these functions, substantial evidence suggests that the mass of nucleotides and nucleosides on airway surfaces is regulated by the rate of ATP release, triggered by breathing-induced mechanical stresses (Button and Boucher 2008). Consistent with this thesis are several studies that have reported that ATP is released from human airway epithelia subjected to physical forces. Examples of these ATP release-stimulating mechanical forces include forces generated by mechanical deformation (Grygorczyk and Hanrahan 1997), fluid shear stress (Tarran et al. 2005), compression/stretch (Button et al. 2007), or osmotic shock (Okada et al. 2006). It should be noted that although the ATP release pathway(s) are poorly understood, studies have suggested that it is the result of vesicular release (Kreda et al. 2007) and/or through conductive ion channels, such CFTR (Egan 2002) and Pannexins (Ransford et al. 2009).

\section{MECHANICAL FORCES IN THE LUNG}

The lung is a unique organ in that it is subjected to complex physical forces during normal tidal breathing, coughing, and vascular perfusion. Over the past few decades, it has been realized that these physical forces play an important role in regulating the structure, function, and metabolism of the lung-for example, the observation that normal breathing, interspersed with intermittent large volume breaths (sighs), is important for maintaining alveolar health and patency (Dietl et al. 2001). Furthermore, breathing movements observed as early as $10 \mathrm{wk}$ of gestation in the human fetus suggest that these mechanical forces are important for cell differentiation and further lung development (Inanlou et al. 2005).

In the airways, two types of mechanical forces dominate. During normal breathing, airflow across the surface of the airway epithelium produces a wall shear stress. Because both airflow velocities and airway diameter decrease proportionally in the deeper lung, it has been estimated that the magnitude of the shear stress force varies little from the large to the small generations of the airways, centering on a value on the order of $\sim 0.5$ dynes $\bullet \mathrm{cm}^{2}$ (Fredberg 1978; Tarran et al. 2005). The other mechanical stress that is relevant during respiration is the transairway pressure gradient. During normal expiration, a transmural pressure gradient of $\sim 8.5 \mathrm{~cm} \mathrm{H}_{2} \mathrm{O}$ is generated (Levitzky 1991), and can approach $\sim 20 \mathrm{~cm} \mathrm{H}_{2} \mathrm{O}$ in the proximal airways during exercise or forced expirations (Jones et al. 1975).

Abnormal physical forces exerted on lung tissues are known to contribute to pathological situations. For example, in extreme conditions, such as patients receiving positive-pressure mechanical ventilation or during severe bronchoconstriction associated with asthma, cells in the lung are compressed and/or stretched to supranormal levels, leading to an array of pathological outcomes, including inflammation, airway remodeling, and even cell death (Ressler et al. 2000). Although transient, mechanical stresses on airways are even more extreme during coughing (Leith 1985). The combination of a closed glottis with the rapid expiratory muscle contraction produces very rapid changes (600$1600 \mathrm{~cm} \mathrm{H}_{2} \mathrm{O} / \mathrm{sec}$ ) in transpulmonary pressures, reaching pressures as high as $200 \mathrm{~cm}$ $\mathrm{H}_{2} \mathrm{O}$ (Basser et al. 1989). During the expiration phase of coughing, peak airflow rates of $>500 \mathrm{~L} / \mathrm{min}$ can be reached, producing wall surface shear stresses estimated to reach as high as 1700 dynes $/ \mathrm{cm}^{2}$ (Basser et al. 1989).

\section{MECHANICAL FORCES AND STIMULATION IN MUCUS CLEARANCE}

As detailed in the sections below, airway clearance therapy (ACT) represents an effective tech- 
nique to facilitate the clearing of retained mucus secretions from the lungs of patients with chronic lung diseases like CF. Although the mechanism of action of such maneuvers on mucus clearance is still poorly understood, it is widely believed that the mechanical forces elicited by these techniques reduce the viscoelasticity of the bronchial mucus secretions. Such forces would be analogous to imparting the "shear-thinning" ketchup; that is, shake the bottle and the semisolid paste becomes a runny liquid. In addition, studies have also shown that ACT can act directly as a physical mucolytic (Sutton et al. 1983), by breaking down of highmolecular-weight DNA in CF sputum samples, to levels comparable to those obtained by exogenous rhDNAse treatment (App et al. 1998). Finally, the ability to generate fluid secretion by the action of mechanically stimulated ATP release during ACT would be expected to reduce the concentration of the mucus (Button et al. 2007). Combined, these effects will make the adhered mucus easier to clear from the lungs.

\section{EXPECTORATION TECHNIQUES}

\section{Cough}

Coughing is the body's natural backup mechanism for airway clearance. The cough is achieved by rapid airflow acceleration and extremely high flow rates and, when coupled with dynamic airway compression, is very effective in squeezing and clearing mucus from the airways (Cloutier 2007). Coughing is mostly reflexive and, thus, does not allow as much conscious control of starting lung volume or pressures developed. However, coughing can be directed in trained patients. During coughing, a deeper inspiration (often around one and one-half times the tidal volume) occurs, increasing elastic recoil. High intrapulmonary pressures are built up behind the glottis, and when the glottis opens, supramaximal, turbulent expiratory flows are generated. During the cough, the posterior membranous portion of the trachea is compressed, and the tracheal diameter is narrowed to about onesixth of normal. With an increase in flow rate of sevenfold during a cough, the linear velocity of air increases 42 -fold. Airflow at the site of com- pression is turbulent and makes the sound that we call a cough. As lung volume decreases and the elastic recoil pressure decreases, the equal pressure point moves upstream toward the alveoli (Cloutier 2007).

The equal pressure point plays a critical role in the effectiveness of coughing, because a substantial increase in airflow velocity occurs at points of narrowing (choke points). High linear airflow velocity provides the turbulent flow, high shearing forces along the airway walls, and high kinetic energies that move secretions cephalad. Because of the extremely high intraluminal and extraluminal pressures generated with a cough, there is more potential for significant dynamic airway collapse at the equal pressure point, especially in unstable airways. Cartilaginous support decreases from the trachea and larger bronchi to the smaller bronchi and is probably minimal within bronchioles. Although smooth muscles may aid in maintaining smaller airway patency, a cough may compress those airways too much to allow effective clearance (Lapin 2002). During a cough, alveolar, pleural, and subglottal pressures may rise as much as $200 \mathrm{~cm} \mathrm{H}_{2} \mathrm{O}$ (Frownfelter and Massery 2006). Coughing will clear to approximately the sixth or seventh generation of segmental bronchi. If a patient has retained secretions, distal airway clearance techniques must move the secretions to an area where the cough can be effective (Frownfelter and Massery 2006).

\section{Movement of the Equal Pressure Point (EPP) during a Forced Expiration ("Huff")}

"Huffing" is a forced expiratory maneuver, usually initiated from mid-to-low lung volumes via an open glottis, and is another way to produce supramaximal airflow and high linear velocities (Rossman et al. 1982). The equal pressure point (EPP) is defined as the point at which the intraluminal pressure and extraluminal pressure are equal. Beyond that point (downstream toward the mouth), the external pressure around the airway (extraluminal or pleural pressure) is greater than the pressure within it (intraluminal), and the airway is compressed, which limits flow. During a huff, the pressure in the airway 
(intraluminal pressure) decreases from the peripheral airways to the mouth, because of frictional pressure loss and convective acceleration pressure loss (Mead et al. 1967). The pressure also decreases because of the movement of air from the periphery with a cumulatively large cross-sectional area, centrally, with gradual cumulative cross-sectional area decreasing. During the exhalation, the extraluminal (pleural) pressure remains relatively constant, and the intraluminal pressure gradually decreases. Thus, there is a wave of equal pressure points moving deeper (more peripherally) into the airways as exhalation proceeds and intraluminal pressures fall.

The site of the equal pressure point is determined by the amount of expiratory force and the elastic recoil. A higher expiratory force shifts the equal pressure point peripherally (toward the alveoli). Likewise, if the forced exhalation is initiated at a lower lung volume, the pressure from the static elastic recoil will be less, as will the intraluminal pressure, and the resulting equal pressure point will be more peripheral.

Mucus clearance has been studied using a two-phase gas-liquid flow mechanism in an in vitro flow model. The study found that the peak expiratory flow rate should exceed the peak inspiratory flow rate by at least $10 \%$ for mucus to move proximally. Second, the peak expiratory flow rate should exceed $30-60 \mathrm{~L} / \mathrm{min}$ to overcome the shear force to which the mucus is attached in order to move the mucus. This study also found that fluids with low viscosity and elasticity required higher expiratory flow rates than viscous fluid to move (Kim et al. 1987).

\section{Asynchronous Ventilation (Differences in Lung Filling) and Interdependence}

For mucus clearance to occur, air must get behind (distal to) the mucus. Even in normal lungs, time constants vary among lung regions, and asynchronous ventilation occurs secondary to regional and stratified inhomogeneity (Murray 1986). Mucus obstruction (partial or complete) in disease states may increase inhomogeneity, substantially impairing the ability to get air past mucus obstructions (Laube et al. 1989). Some airway clearance techniques include an inspiratory pause to compensate for asynchronous ventilation (Lapin 2002).

Inspiration dilates airways as negative pleural pressure causes the lungs to inflate, causing a transient decrease in resistance to airflow that aids in getting air behind the mucus. Interdependence between adjacent parenchymal lung units occurs because of the elasticity of the surrounding interstitium and also between the lungs and chest wall (Mead et al. 1970). These mechanisms help to preserve uniform ventilation distribution. As lung volume decreases during expiration, expiratory flow limitation occurs.

\section{Collateral Ventilation}

The various lobes of the lung are subdivided by fissures. The division into lobes is incomplete, which allows for collateral ventilation. Collateral ventilation is an accessory pathway that connects air spaces supplied by other airways. The accessory pathways in the lung include (1) the channels of Lambert, which connect respiratory bronchioles and terminal bronchioles to air spaces supplied by other airways; (2) the pores of Kohn, which are openings in the alveolar walls that connect adjacent alveoli; and (3) the interbronchiolar channels of Martin. These accessory pathways help to prevent collapse of terminal respiratory units when their supplying airway becomes obstructed (atelectasis) (Cloutier 2007).

\section{Airway Clearance Therapy in CF: Rationale and Practice}

Airway clearance techniques (ACTs) are usually commenced as soon as the diagnosis of CF is made, often soon after birth. In infants, airway clearance techniques are performed by parents and/or caregivers. As children mature, they are taught techniques that can be performed independently of an assistant (Hodson 2000). Patients/caregivers are required to perform this treatment preventatively when well and more intensively during acute exacerbations (Williams 1994). A Consensus Conference Report on CF adult care describes airway clearance therapy as a "cornerstone" of treatment (Yanka- 
skas et al. 2004). Airway clearance techniques are required to have a sound basis in physiology and need to be efficient and effectively applied across the life span.

\section{BREATHING TECHNIQUES TO PROMOTE MUCUS CLEARANCE}

\section{Autogenic Drainage}

Autogenic drainage $(\mathrm{AD})$ is an airway clearance technique underpinned by basic physics, fluid dynamics, pulmonary anatomy, and physiology, together with breathing mechanics (Mead et al. 1967; Dab and Alexander 1979; Chevaillier 1984; Schoni 1989; Lapin 2002; Van Ginderdeuren 2009). J. Chevaillier, the developer of this technique, states that mucus clearance is based on two different systems: the effects of ciliary clearance and increased airflow applying shearing forces to the mucus adhering to the airway wall, similar to the effects of erosion. "The higher the velocity of the medium, the stronger the erosive effect." To achieve the necessary shearing forces to remove secretions from airways, it is necessary to modulate the inspiratory and expiratory airflow.

$\mathrm{AD}$ aims to generate higher expiratory airflow in all generations of bronchi without causing dynamic collapse. This goal is achieved using repetitive controlled tidal volume breathing, starting at lower lung volumes in the vicinity of residual volume (RV) and gradually and progressively increasing lung volumes toward inspiratory reserve volume (IRV) as secretions are loosened, collected, and moved up toward the mouth for expectoration (Van Ginderdeuren 2009). This technique relies on the EPP to move into the more peripheral airways and significantly increase flow rate and linear velocity in these airways (Lapin 2002).

$\mathrm{AD}$ was found to be as effective as other airway clearance techniques when compared in shorter and longer randomized controlled trials (Pfleger et al. 1992; Giles et al. 1995; Miller et al. 1995; McIlwaine et al. 2010; Pryor et al. 2010). The process of airway clearance in AD is based on an active or passive assisted autogenic drainage (AAD) modulation of the airflow and lung volume-based level of breathing. AAD is a technique that can be used with infants and very young children.

\section{Active Cycle of Breathing Technique}

The active cycle of breathing consists of (1) breathing control, (2) thoracic expansion exercises, and (3) a forced expiration technique. Breathing control (BC), which is gentle, relaxed breathing at the patient's own tidal volume and resting respiratory rate, is followed by thoracic expansion exercises (TEEs), which are deep, slow, relaxed inspirations to IRV with or without 2- to 3-sec breath-holds with quiet unforced expirations (elastic recoil). BC is interspersed throughout the cycle to allow recovery and prevent an increase in airflow obstruction. These TEEs help maximize ventilation via collateral channels and interdependence and ameliorate the problem of asynchronous ventilation and blocked airways. The forced expiration technique is a combination of one or more forced expirations (huffs) and periods of breathing control. Huffing to low lung volumes should assist in loosening and mobilizing excess secretions from smaller peripheral airways to larger central airways. When secretions have reached the larger airways, a huff or cough with high lung volume can be used to clear them (Lapin 2002; Pryor 2009). ACBT is either performed in upright sitting or recumbent positions (Cecins et al. 1999). During a forced expiratory maneuver, there is compression of the airway downstream (toward the mouth) from the equal pressure point. The squeezing action, which moves peripherally with decreasing lung volume, together with the increase in air speed as air flows through the narrowed segment, facilitates the movement of secretions along the airway (West 2004). ACBT is comparable to other airway clearance therapies in outcomes commonly used in clinical trials (Pryor et al. 2010; Robinson et al. 2010).

\section{Positive Expiratory Pressure (PEP) Therapy to Enhance Mucus Clearance}

Positive expiratory pressure (PEP) therapy, a flow-regulated technique, was developed in Den- 
mark in the late 1970s using a mask, one-way valve, and selected expiratory orifice resistor. A pressure manometer can be inserted between the valve and the resistor (Falk et al. 1984; Tonnesen and Stovring 1984; Groth et al. 1985; Lannefors 2009). PEP is used to recruit closed or obstructed peripheral airways by mobilizing, transporting, and evacuating secretions in spontaneously breathing patients and is, by definition, combined with the forced expiration technique (FET) described above.

The aim of this flow-regulated technique is to obtain a temporary increase in functional residual capacity (FRC) that allows the tidal volume (TV) to be above the opening volume for otherwise closed or obstructed airways. The 12-15 consecutive TV breaths comprising each cycle should be only slightly active while achieving a mid-expiratory pressure of $10-20 \mathrm{~cm}$ $\mathrm{H}_{2} \mathrm{O}$. Patients should be taught how to recognize a temporary increase in FRC. The number of treatment cycles within a treatment session and the frequency of treatment are individually selected according to specific needs. Owing to the elastic recoil of the lung tissue at this temporarily increased FRC level, collateral ventilation should increase and open up these closed airways. The air in the recruited lung volumes can be used behind secretions and combined with either the forced expiration technique or the technique of autogenic drainage to mobilize, transport, and evacuate airway secretions. This technique can be applied in upright sitting or horizontal positions. PEP can be used in infants held on the arm of the caregiver with the mask applied over the nose and mouth. PEP was found to be superior to postural drainage in short- and longer-term studies (Lannefors and Wollmer 1992; McIlwaine et al. 1997). Contraindications to use of PEP are undrained pneumothorax and frank hemoptysis.

\section{High-Pressure Positive Expiratory Pressure (Hi-PEP) Mucus Clearance Technique}

High-pressure positive expiratory pressure (HiPEP) airway clearance physiotherapy was developed in Graz, Austria during the early 1980s. HiPEP uses forced expiratory maneuvers against the PEP-mask's expiratory resistor for mobilizing and transporting intrabronchial secretions (Oberwaldner et al. 1986). The equipment used is the same as that described in the previous section.

The aim of Hi-PEP is to improve mucus clearance in a physiological way. During the "mobilization" phase, the aim is to increase collateral airflow to underventilated regions and to squeeze "Pendelluft" from hyperinflated into unobstructed and atelectatic lung units. This is achieved using a forced expiration against a marked resistive load. Furthermore, mobilization of mucous plugs is achieved by back pressure-effected dilation of airways. During the "transportation" phase, incorporation of the peripheral airways into the compressed downstream (toward the mouth) segment is a prerequisite for efficacy. An in-depth understanding of the downstream and upstream movement of the equal pressure point is required by therapists teaching patients this technique (Oberwaldner et al. 1991; Pfleger et al. 1992; Zach and Oberwaldner 1992; Oberwaldner 2009).

PEP breathing is undertaken through the mask, two one-way valves, and individually selected expiratory resistors for eight to 10 cycles using moderately increased tidal breathing. This maneuver is followed by inhalation to total lung capacity and one or more forced expiratory maneuvers against the expiratory resistor exhaling toward residual volume. The consequent mobilization of secretions usually results in coughing from low lung volumes into the PEP mask against the resistor, splinting the airways open and avoiding dynamic compression of unstable airways. The sustained expiratory pressures achieved usually range between 40 and $100 \mathrm{~cm}$ $\mathrm{H}_{2} \mathrm{O}$. The individually selected resistor and optimal expiratory pressure is determined by a spirometry-assisted method. Hi-PEP can be applied as a passive physiotherapy technique in infants and patients who are unable to cooperate actively. Contraindications to $\mathrm{Hi}$-PEP include pneumothorax, cardiac disease, frank hemoptysis, lung surgery, and asthma. Hi-PEP is not recommended for patients who are exhausted and unable to meet the demands of this energy-consuming technique. 


\section{Oscillating Positive Expiratory Pressure (OscPEP) Therapy to Enhance Mucus Clearance}

Oscillating positive expiratory pressure using the Flutter device was developed in Europe in the late 1980s (Althaus 1989) and approved by the U.S. FDA in 1994. This was followed by the development of the Acapella device in the United States in the early twenty-first century. The Flutter device uses an oscillating positive expiratory pressure that causes vibrations of the airway wall, which, in turn, loosen secretions, change the rheological properties of sputum to become less viscous, perhaps via promoting ATP release, and prevent premature closure of the bronchi during exhalations (App et al. 1998; Althaus 2009). The Flutter device consists of a molded plastic mouthpiece, a plastic cone, a steel ball, and a perforated cover. By tuning this frequency to the individual's own ventilatory abilities, the patient induces maximal vibrations of the bronchial walls, which promote mucus clearance. The Flutter generates $\mathrm{PEP}$ in the range $18-35 \mathrm{~cm} \mathrm{H}_{2} \mathrm{O}$, and the angle at which the device is held determines the oscillation frequency, usually between 6 and $26 \mathrm{~Hz}$. The patient's expiratory effort determines the pressure. The Acapella device uses a counterweighted plug and magnet to create airflow oscillation. The Acapella device has an adjustable PEP dial that is manipulated to provide more or less PEP during oscillations depending on individual requirements. The performance of these two devices is similar. However, unlike the Flutter, the performance of the Acapella is not dependent on device orientation and may be easier for some patients to use, particularly at low expiratory flows (Volsko et al. 2003). Following use of an oscillating PEP device, mobilized secretions should then be cleared after each cycle by using the forced expiration technique described previously.

Contraindications to oscillating $\mathrm{PEP}$ are frank hemoptysis and an undrained pneumothorax. Caution should be exercised in patients who are unable to tolerate the increased work of breathing and those with increased intracranial pressure; hemodynamic instability; recent fa- cial, oral, or esophageal surgery; acute sinusitis; or middle ear pathology (Althaus 2009). Oscillating PEP therapy has been found to be as effective as other commonly used airway clearance techniques (Morrison and Agnew 2009; Pryor et al. 2010; Sontag et al. 2010).

\section{High-Frequency Chest Wall Oscillation (HFCWO) Therapy}

High-frequency chest wall oscillation (HFCWO) is a patient-delivered form of airway clearance therapy consisting of an inflatable vest and an air-pulse generator, also known as high-frequency chest compression (HFCC). This mechanical system delivers high-frequency chest wall oscillation capable of superimposing oscillatory airflow throughout a patient's inspiratory and expiratory cycle. This is performed by the vest being inflated to a nearly constant background pressure with a superimposed frequency of air pressure oscillations (Hansen and Warwick 1990). During HFCWO, pressure pulses within the vest oscillate the thoracic wall and generate transient increases in airflow within the airways. It has been proposed that HFCWO assists sputum removal by increasing airflow at low lung volumes, increasing expiratory flow bias (creating a peak expiratory flow rate that is $10 \%$ greater than peak inspiratory flow rate), resulting in an increased annular flow of mucus toward the mouth, and decreasing the viscoelasticity of mucus by reducing cross-linking (Fink and Mahlmeister 2002).

HFCWO is usually commenced at low pressures and frequencies and then increased to therapeutic optimum as the patient tolerates. Different devices allow a different range of oscillation and frequency settings. For example, "The Vest" has an adjustable frequency setting that provides delivery of HFCWO at frequencies from 5 to $20 \mathrm{~Hz}$. The pressure delivered to "The Vest" is adjustable with a range of $\sim 3-50 \mathrm{~cm}$ $\mathrm{H}_{2} \mathrm{O}$ and mean pressure of $\sim 25 \mathrm{~cm} \mathrm{H}_{2} \mathrm{O}$. The HFCWO should be paused approximately every 5 min for huffing and coughing.

HFCWO is not recommended with unstable neck injury, intravenous access port being accessed under the vest, pulmonary embolism, 
lung contusion, current hemoptysis, hemodynamic instability, rib fractures, large pleural effusion, or emphysema. Precautions include endstage disease (end expiratory volume may fall below closing capacity), port under the vest (not currently accessed), recent esophageal surgery, distended abdomen, bronchospasm, osteoporosis, and coagulopathy (AARC 1991). HFCWO therapy has been compared with other airway clearance techniques in $\mathrm{CF}$ and other disease groups with pulmonary problems (Arens et al. 1994; Braggion et al. 1995; Kluft et al. 1996; Scherer et al. 1998; Oermann et al. 2001; Phillips et al. 2004; Yuan et al. 2010; Fainardi et al. 2011). A simulation tool to study high-frequency compression energy transfer mechanisms and waveforms has been developed for applications in pulmonary disease (O'Clock et al. 2010). Recently, a large multicenter trial comparing HFCWO therapy with PEP was conducted in 12 centers across Canada in 107 children and adults over a 12-mo period. The HFCWO group experienced significantly more acute exacerbations requiring oral, inhaled, or IV antibiotics than the PEP group. Both groups maintained their lung function over the 1-yr period of the study, although the treatment burden was significantly higher in the HFCWO group. The results of this study favor PEP and do not support the use of HFCWO as the primary form of airway clearance in patients with CF (McIlwaine et al. 2013).

\section{Intrapulmonary Percussive Vibration (IPV)}

Intrapulmonary percussive ventilation (IPV) is a patient-activated form of physiotherapy that is administered via the mouth to the airways, enhances the mobilization and cephalad movement of pulmonary secretions, and increases resting lung volumes. IPV is used to treat and ventilate (short term, during treatment) patients with an obstructive and/or restrictive, acute or chronic respiratory disease.

IPV is an open breathing circuit combining a "Phasitron" with an aerosol converter. The Phasitron is a pressure flow converter that transforms small volumes of gas at high pressure and low flow into larger volumes of gas at low pres- sure and high flow. A high-output nebulizer provides a dense aerosol to deliver medications and hydrate secretions. During IPV, high-frequency minibursts of gas (at 100-300 cycles/ $\mathrm{min}$ ) are superimposed on the patient's own respiration at pressures of $5-35 \mathrm{~cm} \mathrm{H}_{2} \mathrm{O}$. In practice, the driving pressure and frequency are individually titrated to patient comfort and thoracic movement.

IPV creates a global effect of internal percussion of the lungs, which could promote clearance of the peripheral bronchial tree. The highfrequency gas pulses are also proposed to expand the lungs, vibrate and enlarge the airways, and deliver gas into distal lung units, beyond accumulated mucus. Three forms of therapy are provided during IPV: percussive oscillatory vibrations to loosen retained secretions, highdensity aerosol delivery to hydrate viscous mucous plugs, and positive expiratory pressure (PEP) to recruit alveolar lung units. IPV has been compared with other airway clearance therapies in CF and other disease groups (Natale 1994; Homnick 1995; Newhouse 1998; Scherer et al. 1998; Toussaint 2003).

\section{CONSIDERATIONS IN POSITIONING TO OPTIMIZE MUCUS CLEARANCE THERAPY}

\section{Head-Down Tilted Positioning}

A study of CF patients using radiolabeled sputum clearance compared postural drainage, PEP in upright sitting, and cycle exercise versus a control activity (Lannefors and Wollmer 1992). The most effective sputum clearance occurred using PEP in upright sitting. Surprisingly, when the majority of patients were in the left decubitus (head-down) position, there was greater sputum clearance from the dependent left lung compared with the "gravity-assisted" right lung. This study indicates that gravity results in increased ventilation in the dependent regions in positions commonly used during airway clearance, thus effecting increased sputum clearance from the dependent regions. Numerous side effects have been reported in head-down positions, including headaches, sinus pain (Cecins et al. 1999), desaturation of oxygen (Falk et al. 
Mucus Clearance System of the Lung

1984), symptomatic and silent gastroesophageal reflux (Button et al. 1997, 1998, 2003, 2005; Orenstein 2003), and poor adherence (Myers and Horn 2006). Another relevant study compared the effects of body position on mean expiratory pressure (MEP) and peak expiratory flow rate (PEFR), surrogate markers of huff, and cough strength in adults with stable CF. Repeated measures of MEP and PEFR were performed across seven positions (standing, chair-sitting, sitting in bed with backrest vertical, sitting in bed with backrest at $45^{\circ}$, supine, side-lying, and side-lying with head-down tilt $20^{\circ}$ ) in random order. During testing, reflux sensation and oxygenation were monitored. MEP was significantly reduced in side-lying and in the head-down tilt position. PEFRs were significantly reduced in the three-quarters sitting, supine, side-lying, and head-down positions. Oxygenation and reflux scores were worst in the head-down position (Elkins et al. 2005). Patients with respiratory muscle fatigue may have increased respiratory distress in headdown positions due to the added resistive loading beneath the diaphragm because of the weight of the viscera. This may negatively impact airway clearance therapy.

\section{Upright Sitting with Feet Dependent}

Studies using radioactive inert gas with a radiation counter over the chest wall have shown that when radiolabeled gas is inhaled by an individual in the sitting position, radiation counts are lowest in the upper lung fields, intermediate in the mid-lung fields, and greatest in the lower lung fields. This effect of position is gravity dependent. The lower lung fields are preferentially ventilated compared with the upper lung fields. The causes of regional differences in ventilation can be explained in terms of the anatomy of the lung and the mechanics of breathing. An intrapleural pressure gradient exists down the lung. In the upright position, intrapleural pressure tends to be more negative at the top of the lung and becomes progressively less negative toward the bottom of the lung. This pressure is thought to reflect the weight of the suspended lung (Frownfelter and Dean 2006).

\section{Supine}

In the supine position, the apices and bases are ventilated comparably, and the lowermost lung fields are better ventilated than the uppermost. The supine position inherent in bed rest alters the configuration of the chest wall. The normal anteroposterior configuration becomes more transverse. The hemidiaphragms are displaced upward in a cephalad direction, which reduces functional residual capacity (FRC) in this position. If the supine position is adopted for long periods, pulmonary secretions tend to pool on the dependent sides of the airways. The upper side of the airway may dry out, exposing the patient to infection and obstruction (Frownfelter and Dean 2006).

\section{Prone}

The prone position shifts the mobile structures of the thoracic and abdominal cavities. The heart and great vessels are displaced anteriorly. The liver and spleen and kidneys shift caudally. The prone position increases arterial oxygen tension, tidal volume, and dynamic lung compliance. The pleural pressure gradient is homogenized; hence, the distribution of alveolar ventilation and alveolar inflation is augmented (Frownfelter and Dean 2006).

\section{Side-Lying}

In the side-lying position, there is greater gas exchange in the dependent lung. The lower lung fields are preferentially ventilated compared with the upper lung fields. The left lung is smaller than the right to accommodate the position of the heart. This accentuates anteroposterior expansion at the expense of transverse excursion of the dependent chest wall. In this position, the dependent hemidiaphragm is displaced in a cephalad direction because of the compression of the viscera. This results in greater excursion during respiration and to greater contribution to the ventilation to that lung and to gas exchange as a whole in adults (Frownfelter and Dean 2006). Positioning needs careful 
B.M. Button and B. Button

consideration in each individual to optimize airway clearance therapy on an ongoing basis.

\section{Percussion and Vibration}

Manual percussion and vibrations are sometimes used as an adjunct to positioning and the active cycle of breathing. Percussion is used to mobilize mucus and may stimulate coughing in infants and children. Percussion is performed using a cupped hand with a rhythmical flexion and extension action of the wrist. In adults, percussion can be performed with one or two hands. In infants, percussion is performed using two or three fingers of one hand. A literature review by Gallon (1992) suggests that percussion is only indicated in patients with excessive sputum production. Percussion has been shown to cause an increase in hypoxemia (Falk et al. 1984), but, when combined with thoracic expansion exercises, no fall was seen in oxygen saturation (Pryor et al. 1990). Rib fractures were reported in a neonate (Purohit et al. 1975). Vibration augments the expiratory flow and may help mobilize mucus (McCarren and Alison 2006). Percussion and vibration are contraindicated in patients with severe osteoporosis, frank hemoptysis, fractured ribs, and chest injuries. Caution should be exercised in patients with hyper-reactive airways and severe bronchospasm.

\section{Physical Exercise as Airway Clearance}

Whole body physical exercise increases minute ventilation and oxygen uptake via the cardiopulmonary system, uses shear forces to loosen mucus from the airway wall, increases resting lung volumes, and increases regional ventilation via gravitational effects. Exercising in different positions such as upright, sitting, supine, sidelying, and prone leads to the mobilization of pulmonary secretions and enhances airway clearance while concurrently increasing/maintaining cardiorespiratory fitness, general muscle strength, joint mobility, and postural alignment (Zach et al. 1982; Salh et al. 1989; Lannefors and Wollmer 1992; Hebestreit et al. 2001, 2010; Lannefors et al. 2004). Some individuals with mild lung disease and good lung function use exercise together with forced expiration (huffing), coughing, and expectoration as stand-alone airway clearance therapy. Others, with more extensive lung disease and larger volumes of sputum, use exercise as an adjunct to a formal airway clearance therapy regimen (Lannefors 2009; Kuys et al. 2011).

In a recent study of adults with CF, ease of expectoration improved following exercise (Dwyer et al. 2011). Ventilation and respiratory flow were significantly higher during treadmill and cycle exercise compared with control, and there was a significantly greater decrease in sputum mechanical impedance following treadmill walking compared with control but not with cycle ergometry. This last finding is thought to be because of trunk oscillations and increased ventilation and expiratory flow, resulting in increased propulsion of mucus and the creation of shear forces in the airways to augment ATP release airway surface liquid height, and mucus transport toward the oropharynx. Caution should be applied with patients with pulmonary hypertension, cor pulmonale, acute exacerbation with fever, and exercise-induced bronchospasm. Aerobic exercise is recommended as an adjunctive therapy for airway clearance and for its additional benefits to overall health (Flume et al. 2009).

\section{Timing of Airway Clearance and Inhalational Therapies}

Timing of therapies is important in terms of optimizing treatment outcomes. Bronchodilators, if prescribed, are generally inhaled before airway clearance therapy. The mucolytic agent of hypertonic saline is generally prescribed before or during airway clearance (Dentice et al. 2012; Elkins and Dentice 2012). The mucolytic agent dornase alfa is recommended either 30 min before or after airway clearance (Dentice and Elkins 2011).

\section{CONCLUSIONS}

Understanding of mucus clearance from the lung is still expanding and is the focus of a range of diverse investigations. Discoveries made in 
basic science research assist in further understanding the rationale that underpins the different airway clearance therapies. There are many different airway clearance techniques and regimens from which to choose for individual patients. Complete descriptions of the different techniques can be found on the Cystic Fibrosis Worldwide website (www.cfww.org): International Physiotherapy Group/CF, Physiotherapy for people with CF throughout life (4th ed., 2009). These techniques need to be continuously reevaluated and adapted according to changes in pathophysiology, developmental stages, lifestyle, or other considerations.

\section{REFERENCES}

AARC. 1991. AARC (American Association for Respiratory Care) clinical practice guideline. Postural drainage therapy. Respir Care 36: 1418-1426.

Althaus P. 1989. The bronchial hygiene assisted by the flutter VRP1 (Module regulator of a positive pressure oscillation on expiration). Eur Respir J 2 (Suppl 8): 693.

Althaus P. 2009. Oscillating PEP-Flutter therapy. International Physiotherapy Group/Cystic Fibrosis, www.cfww. org.

App EM, Kieselmann R, Reinhardt D, Lindemann H, Dasgupta B, King M, Brand P. 1998. Sputum rheology chang es in cystic fibrosis lung disease following two different types of physiotherapy: Flutter vs autogenic drainage. Chest 114: 171-177.

Arens R, Gozal D, Omlin KJ, Vega J, Boyd KP, Keens TG, Woo MS. 1994. Comparison of high frequency chest compression and conventional chest physiotherapy in hospitalized patients with cystic fibrosis. Am J Respir Crit Care Med 150: 1154-1157.

Basser PJ, McMahon TA, Griffith P. 1989. The mechanism of mucus clearance in cough. J Biomech Eng 111: 288-298.

Benali R, Pierrot D, Zahm JM, de Bentzmann S, Puchelle E. 1994. Effect of extracellular ATP and UTP on fluid transport by human nasal epithelial cells in culture. $A m J$ Respir Cell Mol Biol 10: 363-368.

Bennett WD, Olivier KN, Zeman KL, Hohneker KW Boucher RC, Knowles MR. 1996. Effect of uridine 5'-triphosphate plus amiloride on mucociliary clearance in adult cystic fibrosis. Am J Respir Crit Care Med 153: 1796-1801.

Boucher RC. 1994. Human airway ion transport. Part one. Am J Respir Crit Care Med 150: 271-281.

Boucher RC. 2007a. Airway surface dehydration in cystic fibrosis: Pathogenesis and therapy. Annu Rev Med 58: 157-170.

Boucher RC. 2007b. Evidence for airway surface dehydration as the initiating event in CF airway disease. J Intern Med 261: 5-16.

Braggion C, Cappelletti LM, Cornacchia M, Zanolla L, Mastella G. 1995. Short-term effects of three chest phys- iotherapy regimens in patients hospitalized for pulmonary exacerbations of cystic fibrosis: A cross-over randomized study. Pediatr Pulmonol 19: 16-22.

Button B, Boucher RC. 2008. Role of mechanical stress in regulating airway surface hydration and mucus clearance rates. Respir Physiol Neurobiol 163: 189-201.

Button BM, Heine RG, Catto-Smith AG, Phelan PD, Olinsky A. 1997. Postural drainage and gastro-oesophageal reflux in infants with cystic fibrosis. Arch Dis Child 76: $148-150$.

Button BM, Heine RG, Catto-Smith AG, Phelan PD. 1998. Postural drainage in cystic fibrosis: Is there a link with gastro-oesophageal reflux? J Paediatr Child Health 34: 330-334.

Button BM, Heine RG, Catto-Smith AG, Olinsky A, Phelan PD, Ditchfield MR, Story I. 2003. Chest physiotherapy in infants with cystic fibrosis: To tip or not? A five-year study. Pediatr Pulmonol 35: 208-213.

Button BM, Roberts S, Kotsimbos TC, Levvey BJ, Williams TJ, Bailey M, Snell GI, Wilson JW. 2005. Gastroesophageal reflux (symptomatic and silent): A potentially significant problem in patients with cystic fibrosis before and after lung transplantation. J Heart Lung Transplant 24: $1522-1529$.

Button B, Picher M, Boucher RC. 2007. Differential effects of cyclic and constant stress on ATP release and mucociliary transport by human airway epithelia. J Physiol 580: 577-592.

Button B, Cai L-H, Ehre C, Kesimer M, Hill DB, Sheehan JK, Boucher RC, Rubinstein M. 2012. A periciliary brush promotes the lung health by separating the mucus layer from airway epithelia. Science 337: 937-941.

Cecins NM, Jenkins SC, Pengelley J, Ryan G. 1999. The active cycle of breathing techniques-To tip or not to tip? Respir Med 93: 660-665.

Chevaillier J. 1984. Autogenic drainage. In Cystic fibrosis horizons (ed. Lawson D), p. 235. Wiley, New York.

Cloutier M. 2007. Respiratory physiology. Mosby Elsevier, Philadelphia.

Dab I, Alexander F. 1979. The mechanism of autogenic drainage studied with flow volume curves. Monogr Paediatr 10: 50-53.

Davis CW. 2002. Regulation of mucin secretion from in vitro cellular models. Novartis Found Symp 248: 113-131, 277-282.

Davis IC, Matalon S. 2007. Epithelial sodium channels in the adult lung-Important modulators of pulmonary health and disease. Adv Exp Med Biol 618: 127-140.

Dentice R, Elkins M. 2011. Timing of dornase alfa inhalation for cystic fibrosis. Cochrane Database Syst Rev CD007923.

Dentice RL, Elkins MR, Bye PT. 2012. Adults with cystic fibrosis prefer hypertonic saline before or during airway clearance techniques: A randomised crossover trial. $J$ Physiother 58: 33-40.

Dietl P, Haller T, Mair N, Frick M. 2001. Mechanisms of surfactant exocytosis in alveolar type II cells in vitro and in vivo. News Physiol Sci 16: 239-243.

Dwyer TJ, Alison JA, McKeough ZJ, Daviskas E, Bye PT. 2011. Effects of exercise on respiratory flow and sputum 
B.M. Button and B. Button

properties in patients with cystic fibrosis. Chest 139: 870-877.

Egan ME. 2002. CFTR-associated ATP transport and release. Methods Mol Med 70: 395-406.

Elkins M, Dentice R. 2012. Timing of hypertonic saline inhalation for cystic fibrosis. Cochrane Database Syst Rev 2: CD008816.

Elkins MR, Alison JA, Bye PT. 2005. Effect of body position on maximal expiratory pressure and flow in adults with cystic fibrosis. Pediatr Pulmonol 40: 385-391.

Fainardi V, Longo F, Faverzani S, Tripodi MC, Chetta A, Pisi G. 2011. Short-term effects of high-frequency chest compression and positive expiratory pressure in patients with cystic fibrosis. J Clin Med Res 3: 279-284.

Falk M, Kelstrup M, Andersen JB, Kinoshita T, Falk P, Stovring S, Gothgen I. 1984. Improving the ketchup bottle method with positive expiratory pressure, PEP, in cystic fibrosis. Eur J Respir Dis 65: 423-432.

Fink JB, Mahlmeister MJ. 2002. High-frequency oscillation of the airway and chest wall. Respir Care 47: 797-807.

Fischer H, Illek B, Machen TE. 1998. Regulation of CFTR by protein phosphatase $2 \mathrm{~B}$ and protein kinase C. Pflugers Arch 436: 175-181.

Flume PA, Mogayzel PJ Jr, Robinson KA, Goss CH, Rosenblatt RL, Kuhn RJ, Marshall BC. 2009. Cystic fibrosis pulmonary guidelines: Treatment of pulmonary exacerbations. Am J Respir Crit Care Med 180: 802-808.

Fredberg JJ. 1978. A modal perspective of lung response. J Acoust Soc Am 63: 962-966.

Frownfelter D, Dean E. 2006. Cardiovascular and pulmonary physical therapy: Evidence and practice. Mosby \& Elsevier Health Sciences, St. Louis, MO.

Frownfelter D, Massery M. 2006. Facilitating airway clearance with coughing techniques. In Cardiovascular and pulmonary physical therapy: Evidence and practice (ed. Frownfelter D, Dean E), pp. 363-376. Mosby \& Elsevier Health Sciences, St. Louis, MO.

Gallon A. 1992. The use of percussion. Physiotherapy 78: 85-89.

Giles DR, Wagener JS, Accurso FJ, Butler-Simon N. 1995. Short-term effects of postural drainage with clapping vs autogenic drainage on oxygen saturation and sputum recovery in patients with cystic fibrosis. Chest 108: 952-954.

Greger R, Schreiber R, Mall M, Wissner A, Hopf A, Briel M, Bleich M, Warth R, Kunzelmann K. 2001. Cystic fibrosis and CFTR. Pflugers Arch 443: S3-S7.

Groth S, Stafanger G, Dirksen H, Andersen JB, Falk M, Kelstrup M. 1985. Positive expiratory pressure (PEPmask) physiotherapy improves ventilation and reduces volume of trapped gas in cystic fibrosis. Bull Eur Physiopathol Respir 21: 339-343.

Grubb BR, Boucher RC. 1998. Effect of in vivo corticosteroids on $\mathrm{Na}^{+}$transport across airway epithelia. Am J Physiol 275: C303-C308.

Grygorczyk R, Hanrahan JW. 1997. CFTR-independent ATP release from epithelial cells triggered by mechanical stimuli. Am J Physiol 272: C1058-C1066.

Hanrahan JW, Mathews CJ, Grygorczyk R, Tabcharani JA, Grzelczak Z, Chang XB, Riordan JR. 1996. Regulation of the CFTR chloride channel from humans and sharks. $J$ Exp Zool 275: 283-291.

Hansen LG, Warwick WJ. 1990. High-frequency chest compression system to aid in clearance of mucus from the lung. Biomed Instrum Technol 24: 289-294.

Hebestreit A, Kersting U, Basler B, Jeschke R, Hebestreit H. 2001. Exercise inhibits epithelial sodium channels in patients with cystic fibrosis. Am J Respir Crit Care Med 164: $443-446$.

Hebestreit H, Kieser S, Junge S, Ballmann M, Hebestreit A, Schindler C, Schenk T, Posselt HG, Kriemler S. 2010. Long-term effects of a partially supervised conditioning programme in cystic fibrosis. Eur Respir J 35: 578-583.

Hodson ME. 2000. Treatment of cystic fibrosis in the adult. Respiration 67: 595-607.

Homnick DN, Anderson K, Marks JH. 1998. Comparison of the flutter device to standard chest physiotherapy in hospitalized patients with cystic fibrosis: A pilot study. Chest 114: 993-997.

Inanlou MR, Baguma-Nibasheka M, Kablar B. 2005. The role of fetal breathing-like movements in lung organogenesis. Histol Histopathol 20: 1261-1266.

Johnson FL, Donohue JF, Shaffer CL. 2002. Improved sputum expectoration following a single dose of INS316 in patients with chronic bronchitis. Chest 122: 2021-2029.

Jones DP, Ellam SV, Riddle H, Watson BW. 1975. The measurement of air flow in a forced expiration using a pressure-sensitive transistor. Med Biol Eng 13: 71-77.

Kim CS, Iglesias AJ, Sackner MA. 1987. Mucus clearance by two-phase gas-liquid flow mechanism: Asymmetric periodic flow model. J Appl Physiol 62: 959-971.

Kluft J, Beker L, Castagnino M, Gaiser J, Chaney H, Fink RJ. 1996. A comparison of bronchial drainage treatments in cystic fibrosis. Pediatr Pulmonol 22: 271-274.

Knowles MR, Clarke LL, Boucher RC. 1991. Activation by extracellular nucleotides of chloride secretion in the airway epithelia of patients with cystic fibrosis. $N$ Engl J Med 325: $533-538$.

Kreda SM, Gynn MC, Fenstermacher DA, Boucher RC, Gabriel SE. 2001. Expression and localization of epithelial aquaporins in the adult human lung. Am J Respir Cell Mol Biol 24: 224-234.

Kreda SM, Okada SF, van Heusden CA, O’Neal W, Gabriel S, Abdullah L, Davis CW, Boucher RC, Lazarowski ER. 2007. Coordinated release of nucleotides and mucin from human airway epithelial Calu-3 cells. J Physiol 584: $245-259$.

Kunzelmann K, Schreiber R, Boucherot A. 2001. Mechanisms of the inhibition of epithelial $\mathrm{Na}^{+}$channels by CFTR and purinergic stimulation. Kidney Int 60: 455461.

Kunzelmann K, Bachhuber T, Regeer R, Markovich D, Sun J, Schreiber R. 2005. Purinergic inhibition of the epithelial $\mathrm{Na}^{+}$transport via hydrolysis of PIP2. FASEB J 19: $142-143$.

Kuys SS, Hall K, Peasey M, Wood M, Cobb R, Bell SC. 2011. Gaming console exercise and cycle or treadmill exercise provide similar cardiovascular demand in adults with cystic fibrosis: A randomised cross-over trial. J Physiother 57: 35-40. 
Lannefors L. 2009. Positive expiratory pressure. Internationa Physiotherapy Group/Cystic Fibrosis, http://www.cfww. org.

Lannefors L, Wollmer P. 1992. Mucus clearance with three chest physiotherapy regimes in cystic fibrosis: A comparison between postural drainage, PEP and physical exercise. Eur Respir J 5: 748-753.

Lannefors L, Button BM, McIlwaine M. 2004. Physiotherapy in infants and young children with cystic fibrosis: Current practice and future developments. JR Soc Med 97: 8-25.

Lapin CD. 2002. Airway physiology, autogenic drainage, and active cycle of breathing. Respir Care 47: 778-785.

Laube BL, Links JM, LaFrance ND, Wagner HN Jr, Rosenstein BJ. 1989. Homogeneity of bronchopulmonary distribution of $99 \mathrm{mTc}$ aerosol in normal subjects and in cystic fibrosis patients. Chest 95: 822-830.

Lazarowski ER, Boucher RC. 2001. UTP as an extracellular signaling molecule. News Physiol Sci 16: 1-5.

Lazarowski ER, Boucher RC. 2009. Purinergic receptors in airway epithelia. Curr Opin Pharmacol 9: 262-267.

Lazarowski ER, Mason SJ, Clarke L, Harden TK, Boucher RC. 1992. Adenosine receptors on human airway epithelia and their relationship to chloride secretion. $\mathrm{Br}$ J Pharmacol 106: 774-782.

Leith DE. 1985. The development of cough. Am Rev Respir Dis 131: S39-S42.

Levitzky MG. 1991. Pulmonary physiology. McGraw-Hill, New York.

McCarren B, Alison JA. 2006. Physiological effects of vibration in subjects with cystic fibrosis. Eur Respir $J$ 27: 1204-1209.

Mcllwaine PM, Wong LT, Peacock D, Davidson AG. 1997. Long-term comparative trial of conventional postural drainage and percussion versus positive expiratory pressure physiotherapy in the treatment of cystic fibrosis. $J$ Pediatr 131: 570-574.

McIlwaine M, Wong LT, Chilvers M, Davidson GF. 2010. Long-term comparative trial of two different physiotherapy techniques; postural drainage with percussion and autogenic drainage, in the treatment of cystic fibrosis. Pediatr Pulmonol 45: 1064-1069.

Mcllwaine MP, Alarie N, Davidson GF, Lands LC, Ratjen F, Milner R, Owen B, Agnew JL. 2013. Long-term multicentre randomised controlled study of high frequency chest wall oscillation versus positive expiratory pressure mask in cystic fibrosis. Thorax doi: 10.1136/thoraxjnl2012-202915.

Mead J, Turner JM, Macklem PT, Little JB. 1967. Significance of the relationship between lung recoil and maximum expiratory flow. J Appl Physiol 22: 95-108.

Mead J, Takishima T, Leith D. 1970. Stress distribution in lungs: A model of pulmonary elasticity. J Appl Physiol 28: $596-608$.

Miller S, Hall DO, Clayton CB, Nelson R. 1995. Chest physiotherapy in cystic fibrosis: A comparative study of autogenic drainage and the active cycle of breathing techniques with postural drainage. Thorax 50: 165-169.

Morrison L, Agnew J. 2009. Oscillating devices for airway clearance in people with cystic fibrosis. Cochrane Database Syst Rev CD006842.
Morse DM, Smullen JL, Davis CW. 2001. Differential effects of UTP, ATP, and adenosine on ciliary activity of human nasal epithelial cells. Am J Physiol Cell Physiol 280: C1485-C1497.

Murray JF. 1986. Ventilation. In The normal lung (The basis for diagnosis and treatment of pulmonary disease) (ed. Murray JF), pp. 114-117. W.B. Saunders, Philadelphia.

Myers LB, Horn SA. 2006. Adherence to chest physiotherapy in adults with cystic fibrosis. J Health Psychol 11: 915-926.

Natale JE, Pfeifle J, Homnick DN. 1994. Comparison of intrapulmonary percussive ventilation and chest physiotherapy: A pilot study in patients with cystic fibrosis. Chest 105: 1789-1793.

Newhouse PA, White F, Marks JH, Homnick DN. 1998. The intrapulmonary percussive ventilator and flutter device compared to standard chest physiotherapy in patients with cystic fibrosis. Clin Pediatr 37: 427-432.

Oberwaldner B. 2009. Hi-PEP. International Physiotherapy Group/Cystic Fibrosis, www.cfww.org.

Oberwaldner B, Evans JC, Zach MS. 1986. Forced expirations against a variable resistance: A new chest physiotherapy method in cystic fibrosis. Pediatr Pulmonol 2: $358-367$.

Oberwaldner B, Theissl B, Rucker A, Zach MS. 1991. Chest physiotherapy in hospitalized patients with cystic fibrosis: A study of lung function effects and sputum production. Eur Respir J 4: 152-158.

O’Clock GD, Lee YW, Lee J, Warwick WJ. 2010. A simulation tool to study high-frequency chest compression energy transfer mechanisms and waveforms for pulmonary disease applications. IEEE Trans Biomed Eng 57: 1539-1546.

Oermann CM, Sockrider MM, Giles D, Sontag MK, Accurso FJ, Castile RG. 2001. Comparison of high-frequency chest wall oscillation and oscillating positive expiratory pressure in the home management of cystic fibrosis: A pilot study. Pediatr Pulmonol 32: 372-377.

Okada SF, Nicholas RA, Kreda SM, Lazarowski ER, Boucher RC. 2006. Physiological regulation of ATP release at the apical surface of human airway epithelia. J Biol Chem 281: 22992-23002.

Orenstein DM. 2003. Heads up! Clear those airways! Pediatr Pulmonol 35: 160-161.

Pfleger A, Theissl B, Oberwaldner B, Zach MS. 1992. Selfadministered chest physiotherapy in cystic fibrosis: A comparative study of high-pressure PEP and autogenic drainage. Lung 170: 323-330.

Phillips GE, Pike SE, Jaffe A, Bush A. 2004. Comparison of active cycle of breathing and high-frequency oscillation jacket in children with cystic fibrosis. Pediatr Pulmonol 37: 71-75.

Picher M, Burch LH, Boucher RC. 2004. Metabolism of P2 receptor agonists in human airways: Implications for mucociliary clearance and cystic fibrosis. J Biol Chem 279: 20234-20241.

Pryor JA. 2009. Active cycle of breathing techniques. International Physiotherapy Group/Cystic Fibrosis, www.cfww. org.

Pryor JA, Webber BA, Hodson ME. 1990. Effect of chest physiotherapy on oxygen saturation in patients with cystic fibrosis. Thorax 45: 77. 
B.M. Button and B. Button

Pryor JA, Tannenbaum E, Scott SF, Burgess J, Cramer D, Gyi K, Hodson ME. 2010. Beyond postural drainage and percussion: Airway clearance in people with cystic fibrosis. J Cyst Fibros 9: 187-192.

Purohit DM, Caldwell C, Levkoff AH. 1975. Letter: Multiple rib fractures due to physiotherapy in a neonate with hyaline membrane disease. Am J Dis Child 129: 1103-1104.

Ransford GA, Fregien N, Qiu F, Dahl G, Conner GE, Salathe M. 2009. Pannexin 1 contributes to ATP release in airway epithelia. Am J Respir Cell Mol Biol 41: 525-534.

Ressler B, Lee RT, Randell SH, Drazen JM, Kamm RD. 2000. Molecular responses of rat tracheal epithelial cells to transmembrane pressure. Am J Physiol Lung Cell Mol Physiol 278: L1264-L1272.

Robinson KA, McKoy N, Saldanha I, Odelola OA. 2010. Active cycle of breathing technique for cystic fibrosis. Cochrane Database Syst Rev CD007862.

Rock JR, O'Neal WK, Gabriel SE, Randell SH, Harfe BD, Boucher RC, Grubb BR. 2009. Transmembrane protein 16A (TMEM16A) is a $\mathrm{Ca}^{2+}$-regulated $\mathrm{Cl}^{-}$secretory channel in mouse airways. J Biol Chem 284: 1487514880.

Rossman CM, Waldes R, Sampson D, Newhouse MT. 1982. Effect of chest physiotherapy on the removal of mucus in patients with cystic fibrosis. Am Rev Respir Dis 126 $131-135$.

Salh W, Bilton D, Dodd M, Webb AK. 1989. Effect of exercise and physiotherapy in aiding sputum expectoration in adults with cystic fibrosis. Thorax 44: 1006-1008.

Scherer TA, Barandun J, Martinez E, Wanner A, Rubin EM. 1998. Effect of high-frequency oral airway and chest wall oscillation and conventional chest physical therapy on expectoration in patients with stable cystic fibrosis. Chest 113: 1019-1027.

Schmid A, Clunes LA, Salathe M, Verdugo P, Dietl P, Davis CW, Tarran R. 2011. Nucleotide-mediated airway clearance. Subcell Biochem 55: 95-138.

Schoni MH. 1989. Autogenic drainage: A modern approach to physiotherapy in cystic fibrosis. J R Soc Med 82: 32-37.

Sontag MK, Quittner AL, Modi AC, Koenig JM, Giles D, Oermann CM, Konstan MW, Castile R, Accurso FJ. 2010. Lessons learned from a randomized trial of airway secretion clearance techniques in cystic fibrosis. Pediatr Pulmonol 45: 291-300.
Stutts MJ, Lazarowski ER, Paradiso AM, Boucher RC. 1995. Activation of CFTR $\mathrm{Cl}^{-}$conductance in polarized T84 cells by luminal extracellular ATP. Am J Physiol 268: C425-C433.

Sutton PP, Lopez-Vidriero MT, Pavia D, Newman SP, Clarke SW. 1983. Effect of chest physiotherapy on the removal of mucus in patients with cystic fibrosis. Am Rev Respir Dis 127: 390-391.

Tarran R, Button B, Picher M, Paradiso AM, Ribeiro CM, Lazarowski ER, Zhang L, Collins PL, Pickles RJ, Fredberg JJ, et al. 2005. Normal and cystic fibrosis airway surface liquid homeostasis. The effects of phasic shear stress and viral infections. J Biol Chem 280: 3575135759.

Tonnesen P, Stovring S. 1984. Positive expiratory pressure (PEP) as lung physiotherapy in cystic fibrosis: A pilot study. Eur J Respir Dis 65: 419-422.

Toussaint M, de Win H, Steens M, Soudon P. 2003. Effects of intrapulmonary percussive ventilation on mucus clearance in Duchennes muscular dystrophy patients: A preliminary report. Resp Care 48: 940-947.

Van Ginderdeuren F. 2009. Autogenic drainage. International Physiotherapy Group/Cystic Fibrosis, www.cfww.org.

Volsko TA, DiFiore J, Chatburn RL. 2003. Performance comparison of two oscillating positive expiratory pressure devices: Acapella versus Flutter. Respir Care 48: 124-130.

West JB. 2004. Respiratory physiology-The essentials. Lippincott Williams \& Wilkins, Baltimore.

Williams MT. 1994. Chest physiotherapy and cystic fibrosis. Why is the most effective form of treatment still unclear? Chest 106: 1872-1882.

Yankaskas JR, Marshall BC, Sufian B, Simon RH, Rodman D. 2004. Cystic fibrosis adult care: Consensus conference report. Chest 125: 1S-39S.

Yuan N, Kane P, Shelton K, Matel J, Becker BC, Moss RB. 2010. Safety, tolerability, and efficacy of high-frequency chest wall oscillation in pediatric patients with cerebra palsy and neuromuscular diseases: An exploratory randomized controlled trial. J Child Neurol 25: 815-821.

Zach MS, Oberwaldner B. 1992. Effect of positive expiratory pressure breathing in patients with cystic fibrosis. Thorax 47: 66-67.

Zach M, Oberwaldner B, Hausler F. 1982. Cystic fibrosis: Physical exercise versus chest physiotherapy. Arch Dis Child 57: 587-589. 


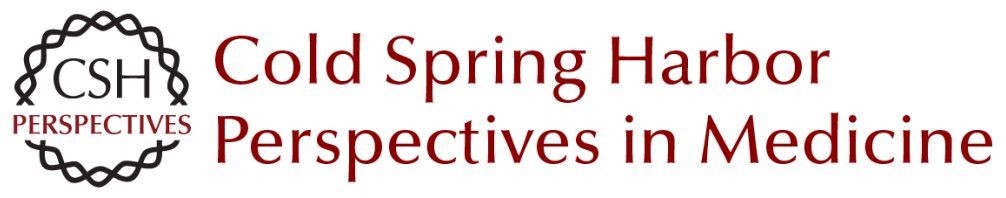

\section{Structure and Function of the Mucus Clearance System of the Lung}

Brenda M. Button and Brian Button

Cold Spring Harb Perspect Med 2013; doi: 10.1101/cshperspect.a009720 originally published online June 10, 2013

\section{Subject Collection Cystic Fibrosis}

Antibiotic and Anti-Inflammatory Therapies for Cystic Fibrosis James F. Chmiel, Michael W. Konstan and J. Stuart Elborn

Structure and Function of the Mucus Clearance System of the Lung Brenda M. Button and Brian Button

New Pulmonary Therapies Directed at Targets Other than CFTR Scott H. Donaldson and Luis Galietta

The Cystic Fibrosis Airway Microbiome Susan V. Lynch and Kenneth D. Bruce

Cystic Fibrosis Transmembrane Conductance Regulator (ABCC7) Structure John F. Hunt, Chi Wang and Robert C. Ford

Status of Fluid and Electrolyte Absorption in Cystic Fibrosis

M.M. Reddy and M. Jackson Stutts

The Influence of Genetics on Cystic Fibrosis

Phenotypes Michael R. Knowles and Mitchell Drumm

Perspectives on Mucus Properties and Formation --Lessons from the Biochemical World Daniel Ambort, Malin E.V. Johansson, Jenny K. Gustafsson, et al.
The Cystic Fibrosis Intestine

Robert C. De Lisle and Drucy Borowitz

Cystic Fibrosis Transmembrane Regulator Correctors and Potentiators Steven M. Rowe and Alan S. Verkman

The Cystic Fibrosis of Exocrine Pancreas Michael Wilschanski and Ivana Novak

Dynamics Intrinsic to Cystic Fibrosis Transmembrane Conductance Regulator Function and Stability

P. Andrew Chong, Pradeep Kota, Nikolay V. Dokholyan, et al.

The Cystic Fibrosis Gene: A Molecular Genetic Perspective Lap-Chee Tsui and Ruslan Dorfman

The CFTR Ion Channel: Gating, Regulation, and Anion Permeation

Tzyh-Chang Hwang and Kevin L. Kirk

Assessing the Disease-Liability of Mutations in CFTR

Claude Ferec and Garry R. Cutting

Supramolecular Dynamics of Mucus Pedro Verdugo

For additional articles in this collection, see http://perspectivesinmedicine.cshlp.org/cgi/collection/ 